\title{
Penerapan Model Problem Based Learning (PBL) Berbantuan Alat Peraga untuk Meningkatkan Minat dan Hasil Belajar Fisika Siswa MA
}

\author{
A. Pujiyanti ${ }^{*}{ }$, Ellianawati ${ }^{2}$, dan W. Hardyanto ${ }^{3}$ \\ Program Pascasarjana Pendidikan Fisika, Universitas Negeri Semarang, Indonesia \\ *Email: arikpujiyanti26@gmail.com
}

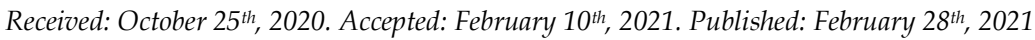

\begin{abstract}
Abstrak
Implementasi kurikulum 2013 memunculkan beberapa inovasi dalam proses pembelajaran termasuk menggunakan model PBL. Penelitian ini bertujuan untuk mengetahui minat dan hasil belajar peserta didik setelah diberi perlakuan dengan model Problem Based Learning (PBL) berbantuan alat peraga. Jenis penelitian yang digunakan adalah penelitian pra-eksperimental dengan rancangan one-shot case study. Sampel penelitian terdiri atas 14 peserta didik MA Uswatun Hasanah Semarang. Teknik pengumpulan data menggunakan instrumen tes tertulis dan angket minat belajar peserta didik. Hasil penelitian ini menunjukkan bahwa hasil belajar peserta didik yang dianalisis dengan uji $\mathrm{N}$-gain mengalami peningkatan dengan koefisien $\mathrm{N}$ gain 0,21 yang termasuk pada kriteria rendah. Persentase minat belajar peserta didik diperoleh hasil rata-rata sebesar 81,786\% sehingga deikategorikan sangat baik. Hasil penelitian juga menunjukkan penggunaan model PBL memeroleh ketuntasan hasil belajar materi Gerak Melingkar sebesar $85 \%$ sehingga dapat disimpulkan bahwa model PBL berbantuan alat peraga memiliki pengaruh terhadap hasil belajar peserta didik.
\end{abstract}

\begin{abstract}
The implementation of the 2013 curriculum led to several innovations in the learning process including using the Problem Based Learning (PBL) model. This study aims to determine the interests and learning outcomes of students after being treated with the PBL model assisted by teaching aids. This type of
\end{abstract}


research is a pre-experimental study with a one-shot case study design. The research sample consisted of 14 students of MA Uswatun Hasanah Semarang. The data collection technique used a written test instrument and a student interest questionnaire. The results of this study indicate that the learning outcomes of students analyzed by the $\mathrm{N}$-gain test have increased with an $\mathrm{N}$-gain coefficient of 0.21 which is included in the low criteria. The percentage of students' interest in learning obtained an average result of $81.786 \%$ so that it is categorized as very good. The results also showed that the use of the PBL model resulted in $85 \%$ completeness of the learning outcomes of the Circular Motion material so it could be concluded that the PBL model assisted by teaching aids had an influence on the learning outcomes of students. (2021PERJ

Keywords: Interest to Learn; Learning outocomes; PBL (Problem Based Learning).

\section{PENDAHULUAN}

Pendidikan merupakan kegiatan yang terencana untuk mewujudkan proses belajar mengajar dengan tujuan mengembangkan potensi peserta didik, agar memiliki kemampuan KI 1, KI 2, KI 3, dan KI 4 (Yulianto, Tusmiyati, \& Widiastuti, 2020). Pembahasan tentang pendidikan tidak dapat terlepas dari pembelajaran di sekolah.

Tujuan pembelajaran adalah untuk memeroleh perubahan tingkah laku setiap peserta didik yang dikarenakan adanya proses pembelajaran (Ismail, 2011). Pendidik diharapkan tidak hanya sekedar menyampaikan materi untuk mentransfer konsep pada proses pembelajaran, tetapi juga dapat mengaktifkan peserta didik agar pembelajaran lebih efektif
(Jannah, Rahmawati, \& Reffiane, 2020). Guru harus menyadari bahwa setiap peserta didik memiliki cara yang berbeda untuk belajar dan memahami informasi baru, sehingga perlu dibimbing dengan berbagai model yang ada serta media dengan menyesuaikan kondisi saat ini. Hal ini bertujuan untuk memaksimalkan informasi yang dapat peserta didik pahami dalam kegiatan belajar mengajar (Wa, Makatita, \& Lisaholit, 2019).

Era globalisasi dalam konteks pendidikan diarahkan pada pembelajaran, inovasi ketrampilan, serta mempertimbangkan kelestarian lingkungan untuk jangka panjang (Fadly, 2017). Keterampilan belajar dan inovasi yang dimaksud adalah kemampuan untuk berpikir kritis dan memecahkan masalah, berkomunikasi dan berkolaborasi, 
serta kreatif dan inovatif (Nurtanto, Moh, \& Sofyan, 2020).

Tujuan dari Kurikulum 2013 yaitu untuk menciptakan peserta didik sebagai penerus bangsa secara integratif (Setyorini, 2020). Pengintegrasian tersebut sebagai upaya memperbaiki peringkat Program for International Student Assessment (PISA) dan TIMSS (Trends in International Mathematics and Science Study) yang peringkatnya semakin menurun. Kurikulum 2013 revisi memiliki beberapa karakteristik, salah satunya pendekatan saintifik dalam proses pembelajaran yang meliputi 5M (Mengamati, Menanya, Mencoba, Mengasosiasi/Menalar, dan Mengkomunikasikan). Akan tetapi, kurikulum 2013 masih mengalami kendala dalam hal capaian (Nurmeipan \& Hermanto, 2020).

Lingkungan belajar di MA Uswatun Hasanah cukup memadai. Namun berdasarkan hasil observasi, terdapat kekurangan media untuk memandu proses pembelajaran. Selain itu, MA Uswatun Hasnah belum memiliki alat peraga fisika yang berkaitan dengan konsep gerak melingkar, sehingga guru untuk mengajak peserta didik agar mencapai tujuan pembelajaran harus lebih kreatif. Permasalahan yang dihadapi di MA Uswatun Hasanah yaitu terbatasnya alat praktikum fisika, sehingga selama proses pembelajaran guru masih kesulitan mengajak peserta didik untuk belajar praktik di laboratorium IPA. Terbatasnya alat praktikum tersebut mennjadi tugas guru untuk menciptakan berbagai karya yang dapat dijadikan sebagai penunjang untuk melakukan praktikum sesuai dengan penerapan kurikulum saat ini.

Implementasi kurikulum 2013 menganjurkan bahwa guru harus lebih inovatif, yaitu dengan memunculkan beberapa inovasi dalam proses pembelajaran termasuk di dalamnya model PBL. Model tersebut digambarkan sebagai model pembelajaran konstruktivisme yang berasumsi bahwa belajar adalah hasil dari interaksi kognitif dan sosial yang berasal dari lingkungan yang berfokus pada suatu masalah (Maskur, Sumarno, \& Rahmawati, 2020).

Pembelajaran fisika sesuai dengan kurikulum Indonesia (K13), bertujuan untuk menumbuhkan sikap ilmiah, mengembangkan keterampilan berpikir dan pengalaman untuk merumuskan masalah, mengusulkan dan memverifikasi hipotesis, mengkomunikasikan hasil eksperimen, memahami konsep fisika, serta mengembangkan IPEK (Kemendikbud, 2014). Penelitian yang bertujuan untuk mengetahui tingkat keterampilan berpikir kritis melalui model pembelajaran PBL telah dilakukan oleh Putri, Pursitasari, \& Rubini (2020). Hasil penelitian tersebut diperoleh tingkat $\mathrm{N}$-gain sebesar $72 \%$ dan respons peserta terhadap penerapan 
pembelajaran dengan model PBL sebesar $81 \%$ dan termasuk kategori baik (Putri, Pursitasari, \& Rubini, 2020).

Melalui model PBL, peserta didik menjadi terbiasa belajar dari masalah aktual dan faktual dalam kehidupan sehari-hari, belajar kelompok dan diskusi untuk mempelajari masalah, mencari informasi yang relevan, mengumpulkan informasi, meninjau alternatif solusi yang ada, dan menyusun tindakan penyelesaian (Mann \& Chang, 2019). Oleh karena itu, peserta didik dapat memahami teori secara mendalam melalui pengalaman praktik pembelajaran empiris. Model tersebut juga memiliki kelemahan misalnya ada beberapa peserta didik yang menghadapi kesulitan untuk berpikir kritis. Berdasarkan kelemahan tersebut, akan lebih efektif jika pendidik menggunakan media yang menarik seperti alat peraga sebagai sarana pembelajaran.

Alat peraga merupakan salah satu media pembelajaran yang dijadikan sebagai sarana menyampaikan pesan dan informasi, sehingga memunculkan minat peserta didik untuk belajar (Sundayana, 2015). Alat peraga juga digunakan untuk memperagakan materi, sehingga peserta didik dapat lebih mudah memahami materi pembelajaran tersebut (Asyhar, 2011).

Salah satu alat peraga yang digunakan sebagai media pembelajaran yaitu alat peraga percepatan sentripetal. Alat peraga tersebut dilengkapi dengan sensor untuk mendeteksi kecepatan sudut dalam satuan rpm pada gerak melingkar. Alat peraga ini sudah berifat otomatis, sehingga peserta didik tidak harus menghitung setiap benda yang mengalami gerak melingkar secara manual. Salah satu tujuan penggunaan alat tersebut adalah agar minat belajar peserta didik meningkat (Slameto, 2010). Minat belajar merupakan faktor instrinsik yang memiliki peran terhadap hasil belajar peserta didik, sedangkan hasil belajar adalah perubahan-perubahan yang terjadi pada diri peserta didik, yang menyangkut 3 aspek (kognitif, afektif, dan psikomotorik) (Purwanto, 2009).

Penelitian yang telah dilakukan oleh Purwanto, dkk (2016) tentang penggunaan model Problem Based Learning (PBL) dengan media power point menyatakan bahwa model PBL jika diterapkan dalam proses pembelajaran tidak hanya memengaruhi hasil belajar peserta didik, tetapi juga memengaruhi minat belajar peserta didik. Adanya integrasi media power point dengan model PBL mendorong peserta didik untuk aktif dalam menyelesaikan dan memecahkan permasalahan yang diberikan oleh guru (Purwanto, Djatmika R.W.W, \& Hariyono, 2016). Model PBL selain diintegrasikan dengan media power point juga dapat diintegrasikan dengan alat peraga. 
Alat peraga yang digunakan dalam penelitian ini yaitu alat peraga sentripetal yang diterapkan dalam pembelajaran. Prinsip kerja alat peraga ini seperti kipas angin, yang memiliki akrilik berbentuk lingkaran serta dapat bergerak melingkar. Alat peraga yang digunakan dalam percobaan bertujuan untuk menentukan percepatan sentripetal, percepatan sudut, kecepatan linier, dan gaya sentripetal. Implementasi model Problem Based Learning (PBL) berbantuan dengan alat peraga dapat membuat peserta didik lebih memahami konsep gerak melingkar yang ditunjukkan dengan peningkatan nilai hasil belajar. Model PBL berbantuan dengan alat peraga diharapkan dapat memberikan peningkatan minat dan hasil belajar yang signifikan kepada peserta didik.

\section{METODE}

Jenis penelitian yang digunakan adalah pra-eksperimental dengan rancangan One-shot Case Study. Penelitian telah dilaksanakan di MA Uswatun Hasanah Semarang. Populasi penelitian terdiri atas 14 peserta didik kelas XII yang telah menerima materi gerak melingkar. Prosedur pengambilan sampel pada penelitian dilakukan dengan teknik sampel jenuh, yaitu dengan menggunakan seluruh anggota populasi sebagai sampel penelitian.

Perangkat pembelajaran yang digunakan yaitu silabus, RPP yang telah divalidasi dengan kelayakan
92,5\%, dan LKPD (Lembar Kerja Peserta Didik) dengan kelayakan $75 \%$ sehingga layak digunakan. Instrumen penelitian yang digunakan yaitu tes hasil belajar berupa soal uraian telah divalidasi dan diperoleh kelayakan $75 \%$. Instrumen yang digunakan untuk mengetahui minat peserta didik terhadap model PBL berbantuan alat peraga adalah angket dengan skala likert.

Teknik analisis data penelitian meliputi teknik analisis hasil belajar dan angket minat peserta didik. Analisis statistik untuk uji normalitas yang digunakan yaitu uji one-sample kolmogorov-smirnov test. Alasan penggunaan uji tersebut dikarenakan sampel yang digunakan terbatas, yaitu 1 kelas. Selain itu, juga dilakukan uji $\mathrm{N}$-gain untuk menganalisis perbedaan hasil belajar peserta didik sebelum diberi dan setelah diberi perlakuan. Sebelum dianalisis menggunakan uji $N$-gain, perlu dilakukan uji one sample t-test. Analisis angket respon peserta didik terhadap penerapan model PBL berbantuan alat peraga dilakukan dengan menghitung ratarata dari empat aspek yaitu implementability, kesinambungan, appropriatene, dan kemenarikan.

\section{HASIL DAN PEMBAHASAN}

Data penelitian diperoleh dari nilai pretest dan posttest peserta didik, serta hasil angket yang diberikan setelah pembelajaran. Hasil analisis data nilai pretest dan nilai posttest menunjukkan rata-rata 
hasil belajar peserta didik sebelum dan setelah diberi perlakuan mengalami sedikit peningkatan yaitu dari rata-rata 72,36 menjadi 78,21 . Hasil analisis one-sample kolmogorov-smirnov test menunjukkan bahwa 14 peserta didik memperoleh nilai rata-rata 72,3571 dengan standar deviasi 2,43. Data tersebut terdistribusi normal berdasarkan hasil analisis data yang diperoleh nilai $\mathrm{D}=0,201(\mathrm{p}>0,05)$ atau $\mathrm{Z}=0,752(\mathrm{p}>0,05)$. Hasil perhitungan Asymp. Sig. (2-tailed) digunakan untuk membuktikan bahwa distribusi yang diamati tidak menyimpang secara signifikan. Hasil dari analisis tersebut diperoleh nilai 0,623 sehingga terdistribusi normal, karena tidak terdapat perbedaan antara data dengan kurva normal.

Data nilai pre-test dan posttest dianalisis menggunakan uji one sample t-test. Uji ini termasuk bagian dari statistik parametrik, sehingga asumsi dasar yang harus terpenuhi adalah data penelitian yang diperoleh harus berdistribusi normal. Uji one sample t-test dalam penelitian ini digunakan untuk membandingkan rata-rata sampel yang diteliti. Hasil analisis dengan uji one sample $t$-test disajikan pada Tabel 1.

Tabel 1. Hasil Analisis One Sample t-Test

\begin{tabular}{|c|c|c|c|c|c|c|}
\hline \multicolumn{7}{|c|}{ Test Value $=73$} \\
\hline & \multirow[t]{2}{*}{$\mathrm{t}$} & \multirow[t]{2}{*}{$\mathrm{df}$} & \multirow[t]{2}{*}{$\begin{array}{l}\text { Sig. (2- } \\
\text { tailed) }\end{array}$} & \multirow[t]{2}{*}{$\begin{array}{c}\text { Mean } \\
\text { Difference }\end{array}$} & \multicolumn{2}{|c|}{$\begin{array}{l}\text { 95\% Confidence } \\
\text { Interval of the } \\
\text { Difference }\end{array}$} \\
\hline & & & & & Lower & Upper \\
\hline Nilai & 0,987 & 13 & 0,342 & 0,64286 & $-2,0500$ & 0,7643 \\
\hline
\end{tabular}

Berdasarkan hasil analisis uji one sample test dapat disimpulkan bahwa Ho diterima karena nilai sig. (2-tailed) $>0,05$. Hasil analisis uji normalitas dengan uji one-sample kolmogorov-smirnov pada nilai posttest disajikan pada Tabel 2.

Tabel 2. Hasil Analisis Uji Normalitas One-Sample Kolmogorov-Smirnov (posttest)

\begin{tabular}{llc}
\hline Kriteria & & Nilai \\
\hline$N$ & & 14 \\
Normal Parameters $(a, b)$ & Mean & 78,2143 \\
& Std. Deviation & 6,68153 \\
Kolmogorov-Smirnov Z & & 0,662 \\
Asymp. Sig. (2-tailed) & & 0,774 \\
\hline
\end{tabular}

Tabel 2 menunjukkan data nilai posttest terdistribusi normal, karena hasil analisis data yang diperoleh nilai $Z=0,662(p>0,05)$. Hasil 
analisis nilai posttest selanjutnya test. Analisis uji one sample test yaitu menggunakan uji one sample disajikan pada Tabel 3 .

Tabel 3. Analisis Uji One Sample Test (Posttest)

\begin{tabular}{|c|c|c|c|c|c|}
\hline \multicolumn{6}{|c|}{ Test Value $=73$} \\
\hline \multirow[t]{2}{*}{$\mathrm{t}$} & \multirow[t]{2}{*}{$\mathrm{df}$} & \multirow[t]{2}{*}{ Sig. (2-tailed) } & \multirow[t]{2}{*}{$\begin{array}{c}\text { Mean } \\
\text { Difference }\end{array}$} & $95 \%$ Con & $\begin{array}{l}\text { Interval of the } \\
\text { nce }\end{array}$ \\
\hline & & & & Lower & Upper \\
\hline 2,920 & 13 & 0,012 & 5,21429 & 1,3565 & 9,0721 \\
\hline
\end{tabular}

Berdasarkan hasil analisis uji one sample test nilai posttest disimpulkan bahwa Ho ditolak dan $\mathrm{H}_{\mathrm{a}}$ diterima. Hal ini menunjukkan bahwa terdapat perbedaan rata-rata nilai pre-test dan posttest. Rata-rata nilai pre-test diperoleh 72,3 sedangkan nilai posttest 78,2 . Hasil penelitian ini sesuai dengan hasil penelitian yang diakukan oleh Malmia, dkk (2019) yaitu terdapat peningkatan hasil belajar setelah menggunakan pembelajaran berbasis masalah. Peningkatan hasil belajar tersebut disebabkan pembelajaran berbasis masalah membantu peserta didik untuk mendapatkan informasi yang sudah ada di benak peserta didik berkaitan dengan pengetahuan dasar dan kompleks. Selain itu, PBL melibatkan peserta didik pada saat pembelajaran untuk menyelesaikan permasalahan yang berkaitan dengan kehidupan nyata, sehingga rasa ingin tahu peserta didik meningkat. Apabila rasa ingin tahu meningkat, maka peserta didik termotivasi untuk belajar sehingga memengaruhi hasil belajar (Malmia, Makatita, \& Lisaholit, 2019).
Hasil belajar peserta didik juga dilihat dari empat indikator soal, yang disajikan pada Tabel 4 . Perbandingan hasil belajar peserta didik juga dapat dilihat dari uji Ngain yaitu membandingkan nilai pre-test dan posttest. Hasil analisis uji $N$-gain disajikan dalam Tabel 5.

Tabel 4. Hasil Belajar Berdasarkan Indikator Soal

\begin{tabular}{lcc}
\hline \multicolumn{1}{c}{ Indikator } & $\begin{array}{c}\text { Capaian } \\
(\%)\end{array}$ \\
\hline $\begin{array}{l}\text { Menentukan besar } \\
\text { perpindahan sudut }\end{array}$ & \\
pada gerak melingkar \\
yang dikaitkan dengan \\
permasalahan \\
kontekstual
\end{tabular}


Tabel 5. Analisis Uji N-gain

\begin{tabular}{cccc}
\hline Kriteria & Jumlah Peserta Didik & N-gain & Keterangan \\
\hline Rendah & 9 & & \\
Sedang & 5 & 0,21 & Rendah \\
Tinggi & 0 & & \\
\hline
\end{tabular}

Tabel 5 menunjukkan bahwa nilai $N$-gain yang diperoleh termasuk kategori kriteria rendah. Rendahnya nilai $N$-gain disebabkan peserta didik baru pertama kali mengenal alat peraga percepatan sentripetal, sehingga masih terdapat kesulitan dalam penggunaan alat peraga yang digunakan. Meskipun nilai $N$-gain yang diperoleh rendah, dapat disimpulkan bahwa hasil belajar peserta didik menggunakan model PBL berbantuan alat peraga pada konsep gerak melingkar mengalami sedikit peningkatan. Media pembelajaran alat peraga percepatan sentripetal yang digunakan selama proses pembelajaran merupakan salah satu faktor eksternal yang membuat peserta didik menjadi lebih tertarik dalam mengikuti pembelajaran fisika.

Minat belajar peserta didik diukur menggunakan angket. Analisis data minat belajar peserta didik dilihat berdasarkan rata-rata persentase pada tiap aspek media yang digunakan. Rata-rata persentase tiap aspek media disajikan pada Tabel 6.

Tabel 6. Minat belajar peserta didik

Aspek

\begin{tabular}{cccc} 
Implementability (\%) & $\begin{array}{c}\text { Kesinambungan } \\
(\%)\end{array}$ & $\begin{array}{c}\text { Appropriatenes } \\
(\%)\end{array}$ & $\begin{array}{c}\text { Kemenarikan } \\
(\%)\end{array}$ \\
\hline 80 & 80,952 & 80 & 86,19 \\
Rata-rata Persentase & & 81,786 & \\
\hline
\end{tabular}

Tabel 6 menunjukkan persentase minat tertinggi terdapat pada aspek kemenarikan. Hal tersebut disebabkan peserta didik mayoritas memiliki keinginan mengeksplor materi dengan alat peraga. Kemampuan eksplorasi dan pemahaman materi dipengaruhi oleh berbagai keterampilan pada saat proses pembelajaran (Susilawati 2020). Aspek implementability memperoleh nilai $80 \%$, dikarenakan terdapat peserta didik yang kesulitan dalam mengoperasikan alat peraga yang digunakan. Pada aspek kesinambungan berkaitan dengan penggunaan alat peraga memperoleh persentase 80,952\%. Hal ini dikarenakan menurut peserta didik, alat peraga yang digunakan sudah sesuai untuk 
memenuhi kebutuhan pembelajaran pada masa kini. Aspek appropriatenes berkaitan dengan kecocokan alat peraga untuk pembelajaran konsep gerak melingkar, memperoleh nilai $80 \%$. Appropriatenes dapat ditumbuhkan dengan bantuan aplikasi sebagai mediadalam proses pembelajaran (Rais et al. 2020). Perbedaan persentase pada tiap aspek disebabkan setiap peserta didik mengalami kendala yang berbeda saat pemakaian alat peraga tersebut. Beradasarkan hasil analisis data, minat belajar peserta didik dikategorikan sangat baik.

\section{KESIMPULAN}

Berdasarkan hasil penelitian yang telah dilakukan disimpulkan bahwa model PBL berbantuan alat peraga dapat meningkatkan hasil belajar secara signifikan. Hal ini dapat dilihat dari nilai rata-rata posttest yang lebih tinggi dari nilai pretest yaitu 78,21 dengan $\mathrm{t}$ ( thitung) diperoleh 2,920. Hal ini menunjukkan bahwa $t_{\text {hitung }}>$ $t_{\text {tabel }}$ maka dapat disimpulkan bahwa pembelajaran menggunakan model PBL dengan berbantuan alat peraga percepatan semtripetal dapat meningkatkan hasil belajar peserta didik. Meningkatnya hasil belajar peserta didik juga dapat dilihat dari hasil analisis $\mathrm{N}$-gain, diperoleh 0,21 dengan kriteria rendah. Minat peserta didik terhadap pembelajaran fisika dengan model PBL berbantuan alat peraga diperoleh skor rata-rata $81,79 \%$ sehingga dapat disimpulkan peserta didik memiliki minat belajar fisika dengan model PBL berbantuan alat peraga yang akhirnya memengaruhi hasil belajar.

\section{DAFTAR PUSTAKA}

Asyhar, R. 2011. Kreatif Mengembangkan Media

Pembelajaran. Jakarta: Gaung Persada (GP) Press.

Fadly, W. 2017. Tinjauan

Kepraktisan Model

Pembelajaran Fisika

"PRODUKSI" Terhadap

Keterlaksanaan Pembelajaran dan Aktivitas Belajar Siswa. Scientiae Educatia: Jurnal Pendidikan Sains, 6 (2), 111-124. Ismail, S. 2011. Strategi Pembelajaran Agama Islam Berbasis PAIKEM.

Semarang: RaSAIL Media Group.

Jannah, A. R., Rahmawati, I., \& Reffiane, F. 2020. Keefektifan Model PBL Berbantu Media Audio-Visual Terhadap Hasil Belajar Tema Indahnya Keberagaman Di Negeriku. Mimbar PGSD Undiksha, 8(3), 342-350.

Kemendikbud. 2014. Materi

Pelatihan Implementasi

Kurikulum 2013 Tahun Ajaran 2014 Mata Pelajaran Fisika 
SMA/SMK.

Kemendikbud.

Malmia, W., Makatita, S. H., \& Lisaholit, S. 2019. ProblemBased Learning As An Effort To Improve Student Learning Outcomes. International Journal Of Scientific $\mathcal{E}$ Technology Research, 8(9), 1140-1143.

Mann, L., \& Chang, R. 2019. From problem-based learning to practice-based education: a framework for shaping future engineers. European Journal of Engineering Education, 1-21.

Maskur, R., Sumarno, \& Rahmawati, Y. 2020. The Effectiveness of Problem Based Learning and Aptitude Treatment Interaction in Improving Mathematical Creative Thinking Skills on Curriculum 2013. European Journal of Educational Research, 9(1): 375-383.

Noviansyah, M. I., Mursyid, S., \& Sirait, J. (t.thn.). Pengaruh Pembelajaran Gerak Melingkar Beraturan Berbantuan Alat Peraga Portable Board Terhadap Hasil Belajar Siswa. Program Studi Pendidikan Fisika FKIP UNTAN.

Nurmeipan, R., \& Hermanto, F. 2020. Imolementasi Kurikulum 2013 pada Materi IPS Kelas VIII di SMP Sekecamatan Gunungpati. Sosiolium, 2(1), 28-34.
Nurtanto, M., Moh, F., \& Sofyan, H. 2020. Problem Based Learning (PBL) in Industry 4.0: Improving Learning Quality through Character-Based Literacy Learning and Life Career Skill (LL-LCS). Journal of Physics: Conference Series, 110.

Perpusnas. 2003. Dipetik Januari 29, 2021, dari pusdiklat.perpusnas.go.id: pusdiklat.perpusnas.go.id

Purwanto. 2009. Evaluasi Hasil Belajar. Yogyakarta: Pustaka Pelajar.

Purwanto, W., Djatmika R.W.W, E. T., \& Hariyono. 2016. Penggunaan Model Problem Based Learning dengan Media Power Point untuk Meningkatkan Minat Belajar Siswa. Jurnal Pendidikan: Teori, Penelitian, dan Pengembangan, 1(9), 1700-1705.

Putri, C. D., Pursitasari, I. D., \& Rubini, B. 2020. Problem Based Learning Terintegrasi STEM di Era Pandemi Covid-19 untuk Meningkatkan Keterampilan Berpikir Kritis Siswa. JIPI (Jurnal IPA dan Pembelajaran IPA), 4(2): 193-204.

Rais, A.A., Lukman, H. \& Sulistiawati. 2020. Pemahaman Konsep Siswa melalui Model Inkuiri Terbimbing Berbantuan Simulasi PhET. Physics Education Research Journal, 2(1): 1-8 
Setyorini, I. 2020. Pandemi Covid-19 dan Online Learning: Apakah berpengaruh Terhadap Proses Pembelajaran Pada Kurikulum 2013. Journal of Industrial Engineering \& Management Research (JIEMAR), 1(1): 95-102. Slameto. 2010. Belajar dan FaktorFaktor yang Mempengaruhinya. Jakarta: Rineka Cipta.

Sugiyono. 2015. Metodelogi Penelitian Pendidikan. Bandung: Alfabeta. Sundayana. 2015. Statistika Penelitian Pendidikan. Bandung: Alfabeta. Susilawati. 2020. Eksplorasi Konten, Keterampilan Argumentasi, Diskusi Ilmiah, dan Interaksi Keterampilannya Pengetahuan dengan Konseptual
Induksi Magnetik. Jurnal Penelitian Pembelajaran Fisika, 11(1): 69-74.

Wa, M., Makatita, S. H., \& Lisaholit, S. 2019. Problem Based Learning As An Effort to Improve Student Learning Outcomes. International Jounal Of Scientific \& Technology Research, 8(9): 1140-1143.

Yulianto, H. T., Tusmiyati, A., \& Widiastuti, H. 2020. Peningkatan Aktivitas dan Hasil Belajar Siswa Melalui Penerapan Model Problem Based Learning (PBL). Teaching and Learning Journal of Mandalika, 1(2): 104-116. 
Phy. Educ. Res. J. Vol. 3 No. 1 (2021), 41-52 